\title{
Novel curcumin-loaded human serum albumin nanoparticles surface functionalized with folate: characterization and in vitro/vivo evaluation
}

This article was published in the following Dove Press journal:

Drug Design, Development and Therapy

17 August 2016

Number of times this article has been viewed

\author{
Zhiwang Songl,* \\ Yonglin Lu',* \\ Xia Zhangl,* \\ Haiping Wang ${ }^{2}$ \\ Junyi $\mathrm{Han}^{3}$ \\ Chunyan Dong' \\ 'Breast Cancer Center, ${ }^{2}$ Department \\ of Pharmacy, ${ }^{3}$ Department of \\ Gastrointestinal Surgery, Shanghai \\ East Hospital, Tongji University, \\ Shanghai, People's Republic of China \\ *These authors contributed equally \\ to this work
}

Correspondence: Chunyan Dong Breast Cancer Center, Shanghai East Hospital, Tongji University, Shanghai 200120, People's Republic of China Email chunyan_dong@yeah.net

\begin{abstract}
Folate-conjugated, curcumin-loaded human serum albumin nanoparticles (F-CM-HSANPs) were obtained by the chemical conjugation of folate to the surface of the curcumin (CM)-loaded human serum albumin nanoparticles (NPs). The NPs were characterized by various parameters, including size, polydispersity, zeta potential, morphology, encapsulation efficiency, and drug release profile. The mean particle size of F-CM-HSANPs was $165.6 \pm 15.7 \mathrm{~nm}$ (polydispersity index $<0.28$ ), and the average encapsulation efficiency percentage and drug loading percentage of the F-CM-HSANPs were $88.7 \% \pm 4.8 \%$ and $7.9 \% \pm 0.4 \%$, respectively. Applied in vitro, the CM NPs, after conjugation with folate, maintained sustained release, and a faster release of CM was more visibly observed than the unconjugated NPs. F-CM-HSANPs can prolong the retention time of CM significantly in vivo. However, after intravenous injection of F-CM-HSANPs, the pharmacokinetic parameters of CM were not significantly different from those of CM-loaded human serum albumin NPs. The improved antitumor activity of F-CM-HSANPs may be attributable to the protection of drug from enzymatic deactivation followed by the selective localization at the desired site. These results suggest that the intravenous injection of F-CM-HSANPs is likely to have an advantage in the current clinical CM formulation, because it does not require the use of a solubilization agent and it is better able to target the tumor tissue.
\end{abstract}

Keywords: curcumin, folate, HSA nanoparticles, pharmacokinetic parameters

\section{Introduction}

Curcumin (CM), derived from the rhizomes of the herb Curcuma longa Linn, is a natural low-molecular-weight molecule. ${ }^{1}$ It is reported that CM possesses antitumor, antioxidant, antiamyloid, and anti-inflammatory properties. ${ }^{2}$ It is a potent inhibitor of nuclear factor- $\kappa \mathrm{B}$, a transcription factor implicated in the pathogeneses of several malignancies. It can also inhibit the productions of various cytokines, including tumor necrosis factor- $\alpha$ and interleukin- $1 \beta .^{3}$ Preclinical studies have indicated that $\mathrm{CM}$ can inhibit the occurrence of tumors, including breast, cervical, colon, gastric, hepatic, leukemia, oral epithelial, ovarian, pancreatic, and prostate cancer cell lines. ${ }^{4}$ Accordingly, this compound has generated interest in the clinical field as an anticancer agent.

However, the clinical application of $\mathrm{CM}$ has been highly restricted due to its low bioavailability, low serum concentration and tissue distribution, and its quick metabolization, which results from its low aqueous solubility (11 ng/mL at $\mathrm{pH} 5.0)$ and short half-life. ${ }^{5-7}$ In order to solve these problems, researchers have tried different drug formulations to encapsulate $\mathrm{CM}$, such as nanosuspensions, polymeric micelles, cc) hereby accept the Terms. Non-conmercial uses of the work are permitted without any further permisision from Dove Medical Press Linited, provided the work is properly atributed. For permision for commercial use of this work, please see paragraphs 4.2 and 5 of our Terms (https:/ /www.doveperss.om/terms.php). 
nanoparticles (NPs), nanoemulsions, liposomes, conjugates, peptide carriers, cyclodextrins, and solid dispersions..$^{8-11}$

In nanotechnology, human serum albumin (HSA) has attracted a wide range of interest as a carrier system for drug delivery, especially in the field of cancer treatment. ${ }^{12,13}$ It is a nonimmune and nontoxic material and has good biocompatibility and biodegradability. ${ }^{14}$ In addition, albumin nanotechnology does not require surfactants or polymeric materials for preparation. Therefore, it is believed that the tolerance of human serum albumin nanoparticles (HSANPs) in vivo is likely to be good. Abraxane ${ }^{\circledR}$, which is prepared by using albumin carrier, is the best example among the wide range of clinical applications. ${ }^{15}$ In addition, the amino and carboxylic groups of the HSA structure can be used for surface modification. ${ }^{16}$ In the chemotherapeutic treatment of cancer, it was very important to enrich the drug to the tumor cells and simultaneously reduce the drug-associated adverse effects.

Among the targeting ligands, folic acid has been widely used in the colloidal systems that selectively target tumor tissues. The specific advantages of folic acid include small size $(\mathrm{Mw}=441.4 \mathrm{Da})$, low immunogenicity, easy modification, low cost, storage stability, solvent compatibility, and high affinity $\left(K_{\mathrm{d}}=10^{-10} \mathrm{M}\right)$ with the folate receptor alpha. ${ }^{17}$

The main objective of this study was to develop and characterize functionalized HSANPs as the potential carrier for site-specific drug delivery of CM. Folate-conjugated, curcumin-loaded, human serum albumin nanoparticles (F-CM-HSANPs) were prepared by the chemical conjugation of folate to the surface of the curcumin-loaded, human serum albumin nanoparticles (CM-HSANPs). The developed formulations were also characterized by assessing morphology, particle size, zeta potential, encapsulation efficiency (EE), and drug release profile. The cytotoxic activity and anticancer efficacy of the developed formulations were also evaluated in vivo.

\section{Materials and methods}

\section{Materials and animals}

CM (purity $>99 \%$ ) was obtained from Shanghai Yuanye Biopharma Co., Ltd. (Shanghai, People's Republic of China) HSA (purity 96\%-99\%, $65 \mathrm{kDa}$ ) and all other chemicals were obtained from Shanghai Chemical Reagent Company of Chinese Medicine. High-performance liquid chromatography (HPLC)-grade acetonitrile and methanol were obtained from Sigma-Aldrich Co. (St Louis, MO, USA). All other chemicals were of analytical grade. Distilled water was used in all the experiments. HT29 cell lines were obtained from MeiSci Pharma (Shanghai, People's Republic of China).

\section{Preparation of CM-HSANPs}

In this study, the albumin nanotechnology described in the literature was used to prepare CM-HSANPs..$^{18}$ Briefly, $900 \mathrm{mg}$ of HSA was dissolved in $25 \mathrm{~mL}$ of water saturated with chloroform and $100 \mathrm{mg}$ of CM was dissolved in $1.5 \mathrm{~mL}$ of chloroform saturated with water. Afterward, the CM solution was added drop wise into the HSA solution with a stirring rate of $300 \mathrm{rpm}$. Oil/water emulsion was obtained by homogenizing at 20,000 psi for ten cycles. After homogenization, the produced emulsion was rotary evaporated for 20 minutes to allow evaporation of chloroform at $25^{\circ} \mathrm{C}$ under reduced pressure. The NPs were collected after being filtered through a $0.25 \mu \mathrm{m}$ membrane syringe filter, and the solvent was removed by lyophilization for 36 hours at $-70^{\circ} \mathrm{C}$. The CM-HSANPs powder was collected under vacuum for 24 hours at $4^{\circ} \mathrm{C}$.

\section{Preparation of F-CM-HSANPs}

$\mathrm{N}$-Hydroxysuccinimide ester of folic acid (NHS-folate) was prepared according to the previously reported method. ${ }^{19}$ In all, $300 \mathrm{mg}$ of folic acid was dissolved in $6 \mathrm{~mL}$ of anhydrous dimethyl sulfoxide containing $150 \mathrm{~mL}$ of triethylamine, $282 \mathrm{mg}$ of dicyclohexylcarbodiimide, and $156 \mathrm{mg}$ of NHS. The mixture was magnetically stirred overnight at room temperature. The insoluble by-product dicyclohexylurea was removed by filtration. The filtrate was poured into the solution of ice-cold anhydrous ether containing 30\% acetone to precipitate the formation of NHS-folate. The NHS-folate was obtained by centrifugation at $10,000 \mathrm{rpm}$ for 10 minutes at $4{ }^{\circ} \mathrm{C}$ and washed with anhydrous ether. Finally, the product was dried under vacuum.

A total of $5 \mathrm{mg}$ of NHS-folate was dissolved in $1 \mathrm{~mL}$ of carbonate/bicarbonate buffer solution $(0.2 \mathrm{M}, \mathrm{pH} 10)$ and added dropwise to the suspension of CM-HSANPs $(2 \mathrm{~mL}$; $\mathrm{pH}$ was adjusted to ten using $0.2 \mathrm{M}$ carbonate/bicarbonate buffer) with mild stirring. The reaction was allowed to proceed for 1 hour at room temperature. The mixed liquid was centrifuged at 12,000 rpm for 20 minutes and washed with bicarbonate buffer solution. The prepared NPs were freeze dried without other cryoprotectant.

\section{Physicochemical characterization}

The particle size distribution of prepared CM-HSANPs and F-CM-HSANPs was determined by a laser diffraction particle sizer. The measurements were performed at $25^{\circ} \mathrm{C}$ after equilibration for 2 minutes. All analyses were performed in triplicate (with three samples).

The morphology of the CM-HSANPs and F-CMHSANPs was observed under a transmission electron 
microscopy. Before observation, the NPs were prepared as follows: the samples were diluted with distilled water and placed on a copper grid covered with nitrocellulose before negatively stained with phosphotungstic acid and dried at room temperature.

Drug loading (DL) and EE of CM-HSANPs and F-CMHSANPs were identified as follows. Briefly, $0.5 \mathrm{~mL}$ of drug-loaded NP pulp was introduced into preweighed Eppendorf tubes and lyophilized to a constant weight. Then the dried deposits were dissolved and diluted with methanol. The method of HPLC was used to determine the CM amount in solution. Finally, DL and EE of drugloaded NPs were calculated according to the following equations:

$\mathrm{DL}(\%)=\frac{\text { Amount of } \mathrm{CM} \text { in formulation }- \text { Amount of free } \mathrm{CM}}{\text { Weight of formulation (polymer) }} \times 100$

$\mathrm{EE}(\%)=\frac{\text { Amount of } \mathrm{CM} \text { in formulation }- \text { Amount of free } \mathrm{CM}}{\text { Amount of } \mathrm{CM} \text { in formulation }} \times 100$

The concentration of CM in the prepared NPs was determined by HPLC. The chromatographic separation was performed on a column $(\mathrm{C} 18,4.6 \times 250 \mathrm{~mm}, 5 \mu \mathrm{m})$ at the temperature of $30^{\circ} \mathrm{C}$. The mobile phase was a mixture of methanol and water at a ratio of $70: 30(\mathrm{v} / \mathrm{v})$ containing $1 \%$ acetic acid. The flow rate was $1 \mathrm{~mL} / \mathrm{min}$, and the detective wavelength was $428 \mathrm{~nm}$. In all, $10 \mu \mathrm{L}$ of each sample was injected into the column, and blank runs were carried out randomly between samples to allow chromatographic carryover to be evaluated. The retention time of CM was 8.7 minutes.

\section{Storage stability}

Prepared freeze-dried F-CM-HSANPs were stored in closed glass containers at $25^{\circ} \mathrm{C}$ and $60 \%$ relative humidity and examined on the day of production and after 3 months of storage. NPs were analyzed for particle size, DL, EE, and polydispersity index (PDI) at 1-month intervals.

\section{In vitro drug release}

The free CM, CM-HSANPs, and F-CM-HSANPs (containing $20 \mathrm{mg} \mathrm{CM}$ ) were put into three dialysis tubes (molecular weight cut-off 8,000-12,000), respectively, and subjected to dialysis against $50 \mathrm{~mL}$ of normal saline with $1 \%$ Tween 80 in the dark environment at $37^{\circ} \mathrm{C} .{ }^{20}$ In all, $1 \mathrm{~mL}$ of the sample was taken out from the released medium periodically at $0.25,0.5,1,2,4,6,8,10,12,24$, and 36 hours. After each sampling, $1 \mathrm{~mL}$ of fresh normal saline with $1 \%$ Tween 80 was added into the medium to keep the volume constant. HPLC was used for the determination of drug concentration.

\section{Pharmacokinetic study}

Twelve rats weighing between $200 \mathrm{~g}$ and $250 \mathrm{~g}$ were used in this study. The rats were kept under fasting conditions for 24 hours before the experiment started. In this experiment, three groups of rats (six per group) were intravenously administered by tail vein with either CM solution $(10 \mathrm{mg} / \mathrm{kg}$, as a control) or CM-HSANPs $(10 \mathrm{mg} / \mathrm{kg})$ and F-CM-HSANPs formulation (10 mg/kg). In all, $2 \mathrm{~mL}$ of serum samples were collected in pressure equalization tubes at different time intervals before and after drug administration $(0.5,1,2,3,4,6,8,10,12$, and 24 hours). The obtained serum samples were frozen at $-20^{\circ} \mathrm{C}$ until the analysis of HPLC was performed. All animal study protocols and care guidelines were approved by the Institutional Animal Care and Use Committee at the Hospital of Shanghai.

\section{In vivo antitumor activity}

BALB/c male mice (6-7 weeks old) were used as a tumor xenograft model. Tumors were established by inoculating HT 29 cells $\left(5 \times 10^{8}\right.$ cells/mice, $50 \mu \mathrm{L}$ injection $)$ subcutaneously into a dorsal flank of each mouse. Five days after tumor cell inoculation, the mice were administered phosphate-buffered saline, free CM $(10 \mathrm{mg} / \mathrm{kg}$, intravenous [IV], solubilized in Cremophor EL/ethanol), CM-HSANPs, and F-CM-HSANPs $(10 \mathrm{mg} / \mathrm{kg}, \mathrm{IV})$ dissolved in normal saline every other day for 10 days (eight mice in each). A digital caliper was used to measure the tumor diameters, and tumor volumes (in $\mathrm{mm}^{3}$ ) were calculated using the following formula:

$$
\text { Tumor volume }=\text { Length } \times \mathrm{Width}^{2} \times 0.5
$$

The body weights were measured every 2 days in order to monitor the potential toxicities. The in vivo antitumor study was terminated 20 days after injection.

\section{Statistical analysis}

Data were shown as mean $\pm \operatorname{SD}(n=5)$. Statistical data were analyzed by the Student's $t$-test at the level of $P<0.05$.

\section{Results and discussion Physicochemical characterization}

The physicochemical characteristics of F-CM-HSANPs formulations were compared to the corresponding CM-HSANPs (Figure 1). The mean particle size of F-CM-HSANPs $(165.6 \pm 15.7 \mathrm{~nm}, \mathrm{PDI}<0.28)$ was slightly higher, yet deviated by no more than $\pm 30 \mathrm{~nm}$ from that of the corresponding 


\section{A}

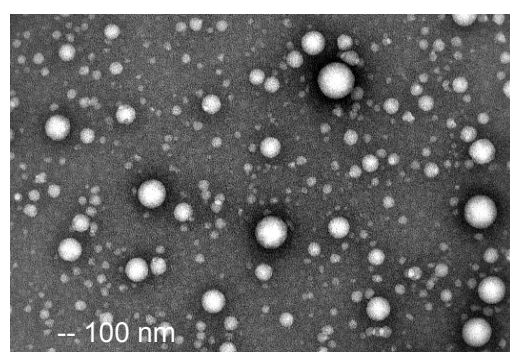

B

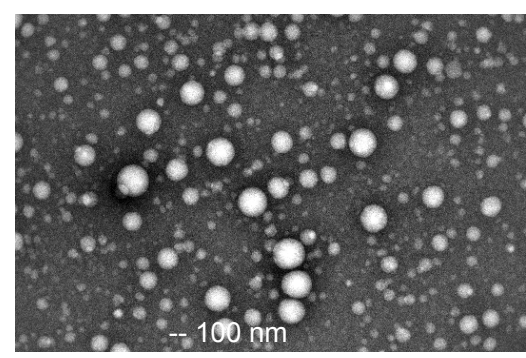

Figure I Transmission electron microscope images of CM-HSANPs $(\mathbf{A})$ and F-CM-HSANPs $(\mathbf{B})(\times 20,000)$.

Abbreviations: CM-HSANPs, curcumin-loaded, human serum albumin nanoparticles; F-CM-HSANPs, folate-conjugated, curcumin-loaded human serum albumin nanoparticles.

CM-HSANPs $(132.2 \pm 9.8 \mathrm{~nm}$, PDI $<0.26)$. The increase in particle size was attributed to the bulkiness provided by folate moiety to the NPs. In the experiment, HSA has a negative charge, so the prepared NPs also exhibited negative zeta potential. Since the folate moiety contains a negative residue in its structure, the zeta potential of folateconjugated NPs $(-27.3 \pm 4.2 \mathrm{mV})$ was slightly more negative than the unconjugated ones $(-21.3 \pm 2.5 \mathrm{mV}) .{ }^{21}$ The average EE\% and DL\% of the CM-HSANPs and F-CM-HSANPs were $86.3 \% \pm 6.8 \%$ and $88.7 \% \pm 4.8 \%$, and $7.5 \% \pm 0.8 \%$ and $7.9 \% \pm 0.4 \%$, respectively.

\section{Storage stability}

The stabilization of our preparations was assessed according to the International Conference on Harmonisation guidelines. After 3 months of storage stabilization at $25^{\circ} \mathrm{C}$ and $60 \%$ relative humidity, lyophilized F-CM-HSANPs appeared to be stable as dried cakes, showing no collapse or contraction. In addition, particle size and PDI measurements showed no change in stability during the storage procedure (Table 1). Long-term stability is a major requirement that must be fully met, and lyophilizing is considered as a viable long-term stability test. Therefore, since HSA acts as a cryoprotectant and aids reconstitution, F-CM-HSANPs were lyophilized with no excipients.

\section{In vitro drug release}

The in vitro release profile of $\mathrm{CM}$ from the free CM, CMHSANPs, and F-CM-HSANPs was studied in normal saline

Table I Storage stability of F-CM-HSANPs at $25^{\circ} \mathrm{C}$ and $60 \%$ $\mathrm{RH}(\mathrm{n}=3)$

\begin{tabular}{lllll}
\hline & 0 day & I month & 2 months & 3 months \\
\hline Particle size $(\mathrm{nm})$ & $\mathrm{I} 65.6 \pm \mathrm{I} 5.7$ & $\mathrm{I} 65.9 \pm 16.2$ & $\mathrm{I} 67.3 \pm \mathrm{I} 5.5$ & $\mathrm{I} 68.4 \pm \mid \mathrm{I} .9$ \\
DL\% & $5.5 \pm 0.7$ & $5.6 \pm 0.8$ & $5.5 \pm 0.5$ & $5.4 \pm 0.6$ \\
EE\% & $83.2 \pm 6.9$ & $81.8 \pm 7.2$ & $82.1 \pm 6.4$ & $80.3 \pm 5.6$ \\
PDI & $<0.28$ & $<0.30$ & $<0.3 \mid$ & $<0.33$ \\
\hline
\end{tabular}

Abbreviations: F-CM-HSANPs, folate-conjugated, curcumin-loaded human serum albumin nanoparticles; $\mathrm{RH}$, relative humidity; DL, drug loading; $\mathrm{EE}$, encapsulation efficiency; PDI, polydispersity index.
(Figure 2). Over time, CM in HSANPs was released much more slowly than free CM. It was clearly observed that the release curve of CM-NPs exhibited a biphasic pattern: an initial burst release during the first 4 hours followed by a slower and sustained release over a long period of time. Owing to the poor water solubility of $\mathrm{CM}$, it was difficult for it to penetrate into the matrix of HSANPs. The diffusion rates of the NPs prepared with HSA in the release medium determine whether it has a good sustained-release performance.

Therefore, the results indicated that the NPs have a good sustained-release function. After conjugated with folate, the CM NPs maintained the properties of sustained release, and a faster release of CM was more visibly observed than the unconjugated NPs. However, there was no obvious difference between the two NPs in the release curve.

To investigate the kinetic modeling of drug release from NPs, the dissolution profiles were fitted to zero-order, $Q=k_{0} \cdot t$; first-order, $\ln (100-Q)=\ln Q_{0}-k_{1} \cdot t$; Higuchi, $Q=k_{\mathrm{H}} \cdot t^{1 / 2}$; and Korsmeyer-Peppas models. ${ }^{22}$ The best-fitted model of rhein released from the NPs was the Higuchi kinetic model; the

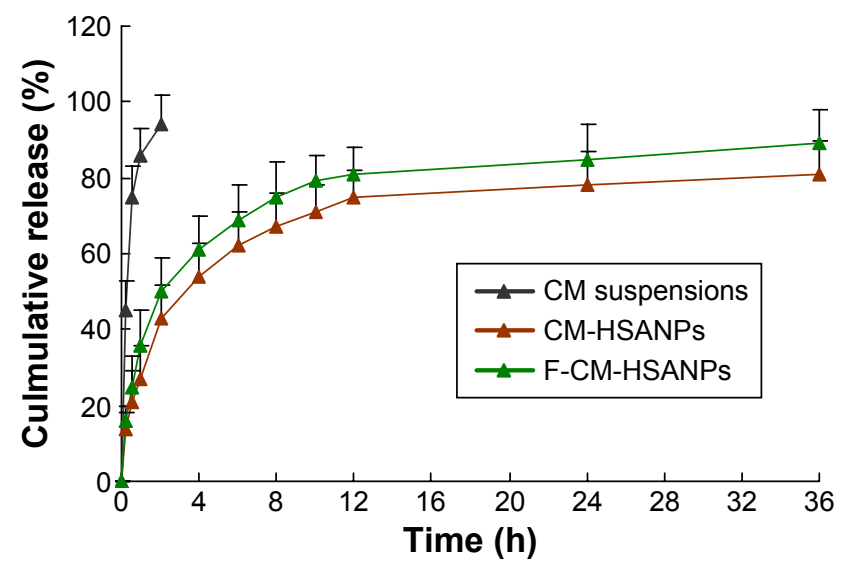

Figure 2 In vitro release of CM from free CM, CM-HSANPs, and F-CM-HSANPs $(n=3)$.

Abbreviations: CM, curcumin; CM-HSANPs, curcumin-loaded, human serum albumin nanoparticles; F-CM-HSANPs, folate-conjugated, curcumin-loaded human serum albumin nanoparticles; $h$, hours. 
correlation coefficient $(r)$ was 0.9991 , revealing that the form of NPs could control the CM release.

\section{Pharmacokinetics studies}

The pharmacokinetics studies of CM solution, CM-HSANPs, and F-CM-HSANPs were conducted in rats (Figure 3). Based on the above results, in the group of CM solution, high concentrations of free $\mathrm{CM}$ in the plasma were recorded 5 minutes after dosing; however, its concentrations decreased rapidly and became nondetectable 6 hours later. In contrast, the concentrations of CM encapsulated in HSANPs could still be determined at 24 hours following injection. The pharmacokinetic results indicated that the clearance of $\mathrm{CM}$ encapsulated in NPs decreased, and preparation of CM into NPs could significantly change the pharmacokinetic behavior of CM. The elimination half-life $\left(t_{1 / 2}\right)$ values of CM-HSANPs and F-CM-HSANPs were 0.36 hours and 0.43 hours, respectively (Table 2). NPs provided higher $\mathrm{AUC}_{0-\infty}$ (2.92-fold) and half-life $\left(t_{1 / 2} ; 5.3\right.$-fold $)$ compared to the free CM. Thus, it was reasonable to conclude that NPs could significantly extend the role of CM in vivo (provided higher bioavailability). This may be due to the fact that a lot of HSA blocks were conjugated to the surface of the NPs, which could substantially increase the circulating time of NPs in the blood. Moreover, there was no significant difference in the pharmacokinetic parameters between F-CM-HSANPs and CM-HSANPs after IV administration, just because there was no obvious difference in the contents of HSA blocks of the two nanosystems.

\section{In vivo antitumor activity}

To evaluate the antitumor activity of F-CM-HSANPs in human colon cancer (HT 29) xenograft models in vivo, we

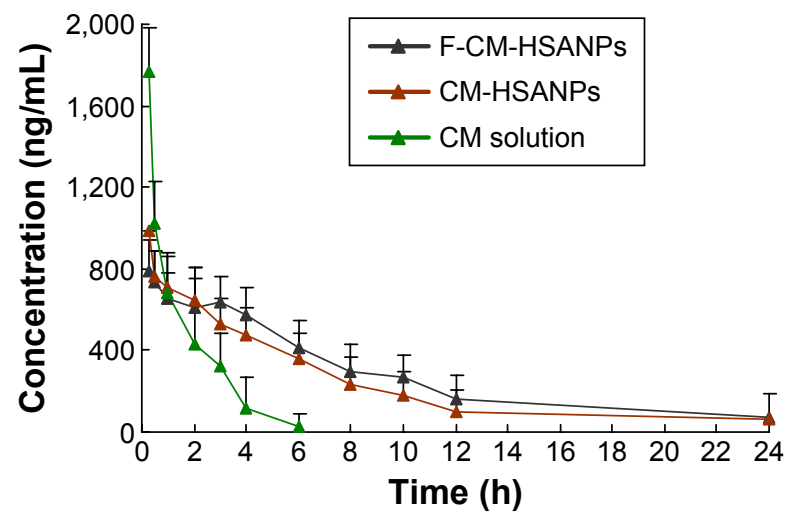

Figure 3 Plasma concentration-time profiles of CM solution, CM-HSANPs, and F-CM-HSANPs after IV administration to rats $(n=6)$.

Abbreviations: CM, curcumin; CM-HSANPs, curcumin-loaded, human serum albumin nanoparticles; F-CM-HSANPs, folate-conjugated, curcumin-loaded human serum albumin nanoparticles; IV, intravenous; h, hours.
Table 2 Pharmacokinetic parameters of CM after IV administration of CM solution, CM-HSANPs, and F-CM-HSANPs to rats $(n=6)$

\begin{tabular}{llll}
\hline Parameter & \multicolumn{3}{l}{ IV administration } \\
\cline { 2 - 4 } & Solution & CM-HSANPs & F-CM-HSANPs \\
\hline$t_{1 / 2}(\mathrm{~h})$ & $0.08 \pm 0.01$ & $0.36 \pm 0.05^{*}$ & $0.43 \pm 0.07^{*}$ \\
$\mathrm{AUC}_{0-\mathrm{t}}(\mathrm{ng} \cdot \mathrm{h} / \mathrm{mL})$ & $2,095.2 \pm 165.3$ & $5,427.3 \pm 487.9^{*}$ & $6,450.9 \pm 632.2^{*}$ \\
$\mathrm{AUC}_{0-\infty}(\mathrm{ng} \cdot \mathrm{h} / \mathrm{mL})$ & $2,298.3 \pm 187.6$ & $5,761.4 \pm 518.5^{*}$ & $6,721.6 \pm 643 . \mathrm{I}^{*}$ \\
$\mathrm{MRT}^{(\mathrm{h})}$ & $2.9 \pm 0.8$ & $13.7 \pm 1.4^{*}$ & $14.7 \pm 1.5^{*}$ \\
$\mathrm{CL}(\mathrm{L} / \mathrm{h})$ & $16.7 \pm 1.8$ & $3.2 \pm 0.6^{*}$ & $3.6 \pm 0.4^{*}$ \\
\hline
\end{tabular}

Note: $* P<0.05$ vs $C M$ solution.

Abbreviations: CM, curcumin; IV, intravenous; CM-HSANPs, curcumin-loaded, human serum albumin nanoparticles; F-CM-HSANPs, folate-conjugated, curcuminloaded human serum albumin nanoparticles; $t_{1 / 2}$, half-life; h, hours; AUC, area under the curve; $M R T$, mean residence time; $C L$, clearance.

examined tumor growths and body weight changes in nude mice treated with saline, free CM, CM-HSANPs, and F-CMHSANPs $(10 \mathrm{mg} / \mathrm{kg})$. Tumors cells were formed at all sites after 5 days of tumor cell injection (Figure 4). The highest growth rate of tumor was found in the saline-treated mice, and free $\mathrm{CM}$ was found to have a slight antitumor effect (18\% tumor growth inhibitions at the end of the treatment). However, CM-HSANPs and F-CM-HSANPs significantly inhibited the growth of HT 29-derived tumors (45\% and 64\%) at the tenth day (Figure 5). The nanocarriers can be transported through the lymphatic system. ${ }^{23,24}$ The antitumor activity of the F-CM-HSANPs was improved, which may be due to the protection of the drug from enzymatic deactivation followed

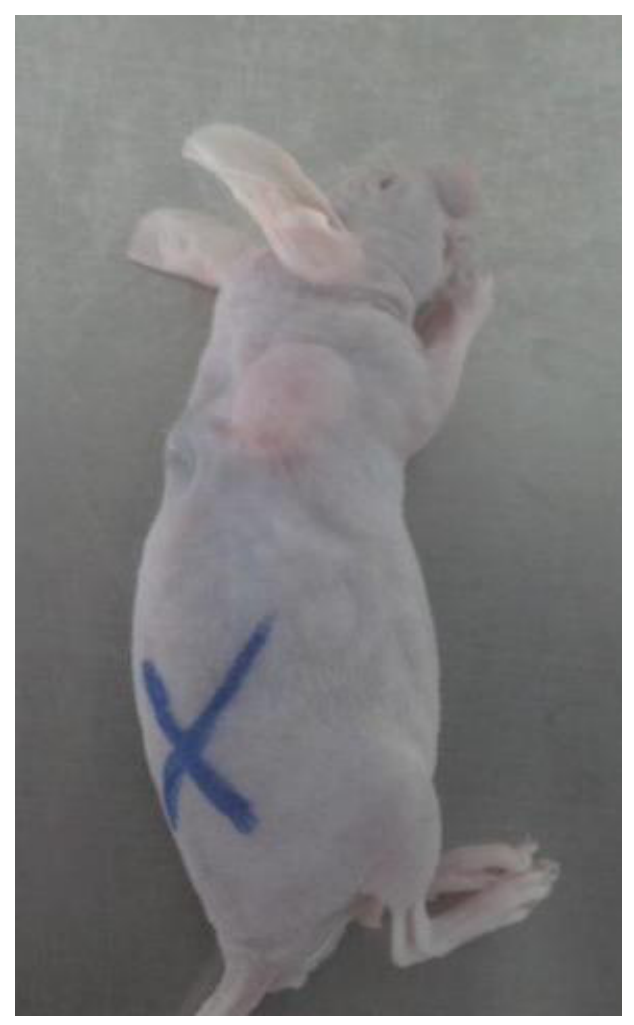

Figure 4 The diagram of human colon cancer (HT 29 cells) xenograft models in vivo. 


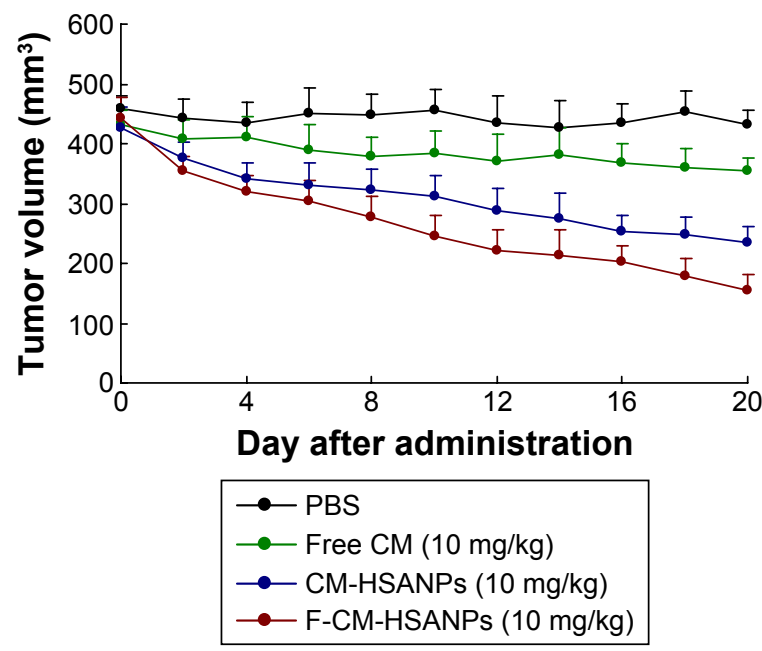

Figure 5 In vivo antitumor activities of free CM, CM-HSANPs, and F-CM-HSANPs (10 mg/kg) in human colon cancer (HT29 cells) xenograft models after the IV administration $(n=8)$.

Abbreviations: CM, curcumin; CM-HSANPs, curcumin-loaded, human serum albumin nanoparticles; F-CM-HSANPs, folate-conjugated, curcumin-loaded human serum albumin nanoparticles; IV, intravenous; PBS, phosphate-buffered saline.

by the selective localization at the desired site. The changes in body weights could reflect the toxicities after the treatments. Animals treated with free CM showed a decrease in body weight vs the control group (phosphate-buffered saline treated), whereas mice given NPs showed no significant reduction in body weight (Figure 6). All results indicated that the IV injection of F-CM-HSANPs is likely to have an advantage in the current clinical CM formulation, because

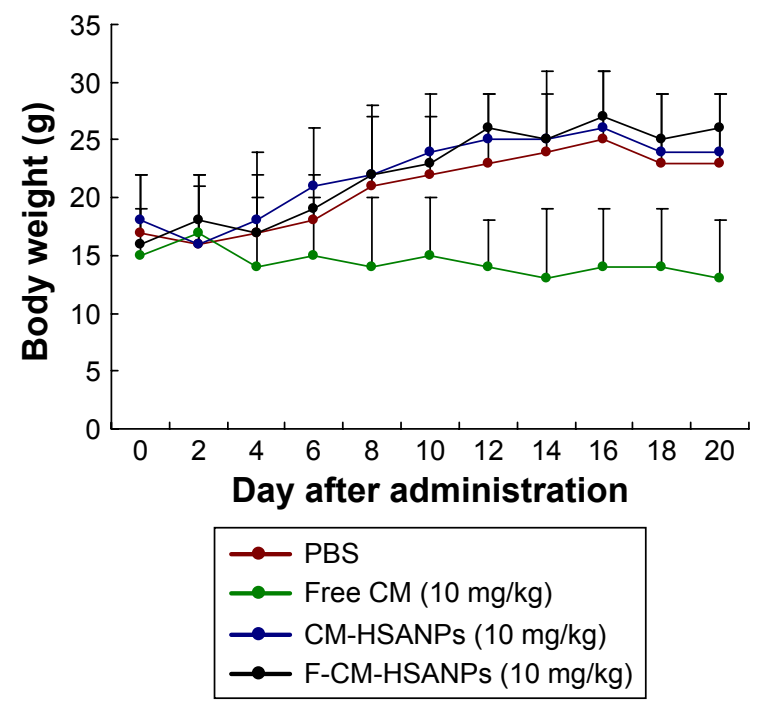

Figure 6 Body weight changes of free CM, CM-HSANPs, and F-CM-HSANPs $(10 \mathrm{mg} / \mathrm{kg})$ in human colon cancer (HT29 cells) xenograft models after the IV administration $(n=8)$.

Abbreviations: CM, curcumin; CM-HSANPs, curcumin-loaded, human serum albumin nanoparticles; F-CM-HSANPs, folate-conjugated, curcumin-loaded human serum albumin nanoparticles; IV, intravenous; PBS, phosphate-buffered saline. it does not require the use of a solubilization agent and is better able to target the tumor tissue.

\section{Conclusion}

In this study, F-CM-HSANPs were obtained by the chemical conjugation of folate to the surface of the CM-HSANPs. The mean particle size of F-CM-HSANPs was 165.6 $\pm 15.7 \mathrm{~nm}$ (PDI $<0.28$, and the average EE\% and DL\% of the F-CMHSANPs were $83.2 \% \pm 6.9 \%$ and $5.5 \% \pm 0.7 \%$, respectively. Applied in vitro, the CM NPs, after conjugated with folate, maintained sustained release, and a faster release of CM was more visibly observed than the unconjugated NPs. In vivo, F-CM-HSANPs can significantly prolong the retention time of CM. However, the pharmacokinetic parameters of $\mathrm{CM}$ after IV administration of F-CM-HSANPs had no obvious difference compared with CM-HSANPs. The improved antitumor activity of the F-CM-HSANPs may be attributable to the protection of the drug from enzymatic deactivation followed by the selective localization at the desired site. These results suggest that the IV injection of F-CM-HSANPs is likely to have an advantage in the current clinical CM formulation, because it does not require the use of a solubilization agent and is better able to target the tumor tissue.

\section{Acknowledgments}

This research was supported in part by the National Nature Science Foundation of China (81573008), the Fund of Pudong Health Bureau of Shanghai (PWRd2014-01), and the Key Disciplines Group Construction Project of Pudong Health Bureau of Shanghai (PWZxq2014-04).

\section{Disclosure}

The authors report no conflicts of interest in this work.

\section{References}

1. Jurenka JS. Anti-inflammatory properties of curcumin, a major constituent of Curcuma longa: a review of preclinical and clinical research. Altern Med Rev. 2009;14(2):141-153.

2. Moghadamtousi SZ, Kadir HA, Hassandarvish P, Tajik H, Abubakar S, Zandi K. A review on antibacterial, antiviral, and antifungal activity of curcumin. Biomed Res Int. 2014;2014:186864.

3. Bar-Sela G, Epelbaum R, Schaffer M. Curcumin as an anti-cancer agent: review of the gap between basic and clinical applications. Curr Med Chem. 2010;17(3):190-197.

4. Kumar G, Mittal S, Sak K, Tuli HS. Molecular mechanisms underlying chemopreventive potential of curcumin: current challenges and future perspectives. Life Sci. 2016;148:313-328.

5. Wegiel LA, Zhao Y, Mauer LJ, Edgar KJ, Taylor LS. Curcumin amorphous solid dispersions: the influence of intra and intermolecular bonding on physical stability. Pharm Dev Technol. 2014;19(8):976-986.

6. Anand P, Kunnumakkara AB, Newman RA, Aggarwal BB. Bioavailability of curcumin: problems and promises. Mol Pharm. 2007;4(6): 807-818 
7. Liu W, Zhai $Y$, Heng X, et al. Oral bioavailability of curcumin: problems and advancements. J Drug Target. 2016:1-9.

8. Hani U, Shivakumar HG. Solubility enhancement and delivery systems of curcumin a herbal medicine: a review. Curr Drug Deliv. 2014;11(6): 792-804.

9. Naksuriya O, Okonogi S, Schiffelers RM, Hennink WE. Curcumin nanoformulations: a review of pharmaceutical properties and preclinical studies and clinical data related to cancer treatment. Biomaterials. 2014;35(10):3365-3383.

10. Siddiqui IA, Sanna V. Impact of nanotechnology on delivery of natural products for cancer prevention and therapy. Mol Nutr Food Res. 2016; 60(6):1330-1341.

11. Mahmood K, Zia KM, Zuber M, Salman M, Anjum MN. Recent developments in curcumin and curcumin based polymeric materials for biomedical applications: a review. Int J Biol Macromol. 2015;81: $877-890$.

12. Dreis S, Rothweiler F, Michaelis M, Cinatl J Jr, Kreuter J, Langer K. Preparation, characterisation and maintenance of drug efficacy of doxorubicin-loaded human serum albumin (HSA) nanoparticles. Int $J$ Pharm. 2007;341(1-2):207-214.

13. Quan Q, Xie J, Gao H, et al. HSA coated iron oxide nanoparticles as drug delivery vehicles for cancer therapy. Mol Pharm. 2011;8(5): 1669-1676.

14. Stollenwerk MM, Pashkunova-Martic I, Kremser C, et al. Albuminbased nanoparticles as magnetic resonance contrast agents: I. Concept, first syntheses and characterisation. Histochem Cell Biol. 2010;133(4): 375-404.

15. Fabi A, Giannarelli D, Malaguti P, et al. Prospective study on nanoparticle albumin-bound paclitaxel in advanced breast cancer: clinical results and biological observations in taxane-pretreated patients. Drug Des Devel Ther. 2015;9:6177-6183.
16. Weber C, Kreuter J, Langer K. Desolvation process and surface characteristics of HSA-nanoparticles. Int J Pharm. 2000;196(2):197-200.

17. Ulbrich K, Michaelis M, Rothweiler F, et al. Interaction of folateconjugated human serum albumin (HSA) nanoparticles with tumour cells. Int J Pharm. 2011;406(1-2):128-134.

18. Li C, Li Y, Gao Y, et al. Direct comparison of two albumin-based paclitaxel-loaded nanoparticle formulations: is the crosslinked version more advantageous? Int J Pharm. 2014;468(1-2):15-25.

19. Zhang L, Hou S, Mao S, Wei D, Song X, Lu Y. Uptake of folateconjugated albumin nanoparticles to the SKOV3 cells. Int J Pharm. 2004;287(1-2):155-162.

20. Zhao L, Du J, Duan Y, et al. Curcumin loaded mixed micelles composed of Pluronic P123 and F68: preparation, optimization and in vitro characterization. Colloids Surf B Biointerfaces. 2012;97:101-108.

21. Licciardi M, Paolino D, Celia C, Giammona G, Cavallaro G, Fresta M. Folate-targeted supramolecular vesicular aggregates based on polyaspartyl-hydrazide copolymers for the selective delivery of antitumoral drugs. Biomaterials. 2010;31(28):7340-7354.

22. Mehta AK, Yadav KS, Sawant KK. Nimodipine loaded PLGA nanoparticles: formulation optimization using factorial design, characterization and in vitro evaluation. Curr Drug Deliv. 2007;4(3):185-193.

23. Lu H, Li B, Kang Y, et al. Paclitaxel nanoparticle inhibits growth of ovarian cancer xenografts and enhances lymphatic targeting. Cancer Chemother Pharmacol. 2007;59(2):175-181.

24. Zhang XY, Lu WY. Recent advances in lymphatic targeted drug delivery system for tumor metastasis. Cancer Biol Med. 2014;11(4):247-254.
Drug Design, Development and Therapy

\section{Publish your work in this journal}

Drug Design, Development and Therapy is an international, peerreviewed open-access journal that spans the spectrum of drug design and development through to clinical applications. Clinical outcomes, patient safety, and programs for the development and effective, safe, and sustained use of medicines are the features of the journal, which

\section{Dovepress}

has also been accepted for indexing on PubMed Central. The manuscript management system is completely online and includes a very quick and fair peer-review system, which is all easy to use. Visit http://www.dovepress.com/testimonials.php to read real quotes from published authors.

Submit your manuscript here: http://www.dovepress.com/drug-design-development-and-therapy-journal 